\title{
"GUIGUIBASHOW". MENINO-ADULTO ESPETÁCULO. Mercantilização da infância em tempos de Instagram
}

\author{
Marta Maria Azevedo Queiroz * \\ Flalrreta Alves dos Santos Moura Fé **
}

\section{Resumen}

O artigo é uma reflexão produto da investigação sobre a relação entre os meios e a infância na era da Internet, em específico na rede social Instagram, com o propósito de entender a mercantilização dessas crianças por meio da capitalização da sua imagem como estratégia de venda. O perfil da análise é o de "Guiguibashow", Guillermo, um menino de sete anos de idade que reside em Teresina, capital de Piauí; ele tinha tido fama no Brasil por a imitação do conhecido cantor "Wesley Safadão."

Se conclui que as redes sociais permitem o suplemento do menino para o tempo que o comercializa, transformando-o em "marionete", ferramenta do marketing, apoio de vendas de marcas, produtos e estilos de vida para desenvolver o consumo no mundo globalizado, apresentando-o a favor do capital financeiro das grandes corporações - como adulto em miniatura e ao mesmo tempo que o menino nas espontaneidades e brincadeiras. O lema de "Guiguibashow", recebido e reproduzido pela sua audiência em Instagram é: há vida mais barata, mas não vale a pena."

Palavras chaves: menino, mercantilização, meios de comunicação. Instagram, consumo. Recebido. Março 12, 2018 - Aceitado. Abril 03, 2018

* Professora Doutora do Programa de Pós-Graduação em Comunicação da Universidade Federal do Piauí (UFPI). Brasil. Orcid: https://orcid.org/0000-0001-7253-814X ; E-mail: profa.marta@hotmail.com

** Mestranda do Programa de Pós-Graduação em Comunicação pela Universidade Federal do Piauí (UFPI). E-mail: flalrreta.alves@gmail.com

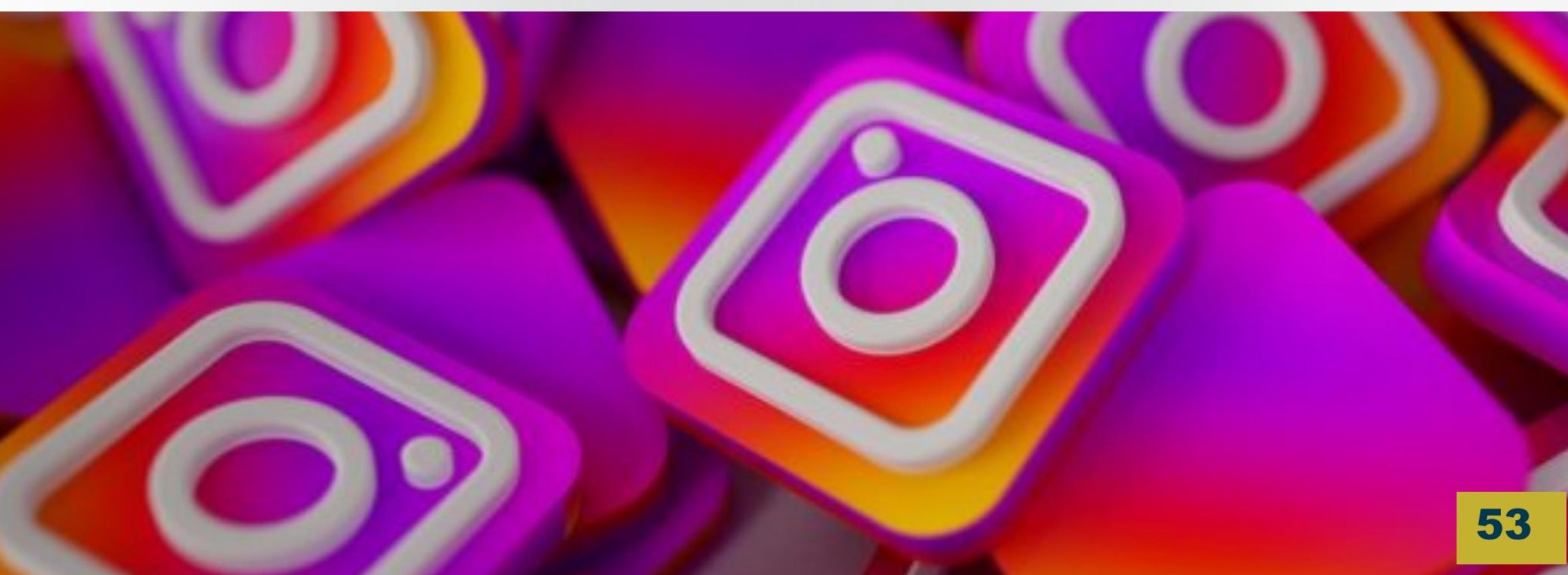




\section{GUIGUIBASHOW'. CHILD_ADULT SHOW. Childhood merchandising in Instagram Age}

\section{Summary}

This is a reflection from a research about the relation between media and childhood in the Internet age, particularly on Instragram social network, in order to understand children merchandising through the capitalization of their image as a sales strategy. "Guiguibashow", The profile of Guillermo, a sevenyear-old child who lives in Teresina-Piaui, was the matter in question; he is known in Brazil because his impersonator of the well- known singer "Wesley Safadão".

It is concluded, that social networks allow the child's incorporation at the same time he is being commercialized, making of him a "puppet", a marketing instrument, sales support of brands and goods, and lifestyles for boosting consumption in the globalized world. he has been showed in favor of financial capital of large corporations - as an adult in miniature, at once as a child in spontaneity and playfulness. Guiguibashow's motto, accepted and replicated by his audience, on Instagram is: "There is cheaper life, but it's not worth it".

Keywords: child, merchandising, mass media, Instagram, consumption. Received. March 12, 2018 - Accepted. April 03, 2018

\section{"GUIGUIBASHOW". NIÑO-ADULTO SHOW. Mercantilización de la infancia en tiempos de Instagram}

\section{Resumen}

El artículo es una reflexión producto de investigación sobre la relación entre los medios y la infancia en la era de Internet, en específico en la red social Instagram, con el propósito de comprender la mercantilización de los niños por medio de la capitalización de su imagen como estrategia de venta. El perfil del análisis es el de "Guiguibashow", Guillermo, un niño de siete años de edad que reside en Teresina, capital de Piauí; ha tenido notoriedad en Brasil por su imitación del conocido cantante "Wesley Safadão".

Se concluye que las redes sociales permiten la inserción del niño al tiempo que lo mercantiliza, convirtiéndolo en "títere", herramienta de marketing, soporte de ventas de marcas, productos y estilos de vida para potenciar el consumo en el mundo globalizado, presentándolo en favor del capital financiero de las grandes corporaciones - como adulto en miniatura y a la vez como niño en sus espontaneidades y jugueteos. El lema de "Guiguibashow", recibido y reproducido por su audiencia en Instagram es: "hay vida más barata, pero no vale la pena".

Palabras Claves: niño, mercantilización, medios de comunicación. Instagram, consumo. Recibido. Marzo 12, 2018 - Aceptado. Abril 03, 2018 


\section{INTRODUÇÃO}

É importante considerar que a presença das mídias digitais está cada vez mais intensa na sociedade contemporânea e a internet tornase uma poderosa ferramenta de 'inserção' e/ou cooptação do público infantil na ambiência virtual, sendo apropriadas pelas grandes corporações do capital financeiro. Assim, o referido artigo, resultado parcial da pesquisa em andamento no Mestrado em Comunicação da Universidade Federal do Piauí (UFPI), visa refletir sobre a relação entre mídia e criança na era da internet, em específico na rede social Instagram, na perspectiva de compreender a mercantilização da infância por meio da capitalização da imagem da criança enquanto estratégia de venda.
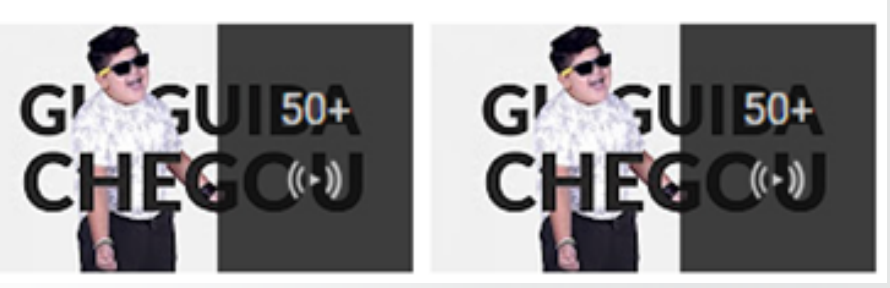

Outra questão a problematizar é a participação das crianças nas mídias e o esmaecimento e/ ou potencialização das linhas fronteiriças entre vida adulta e vida da criança, apresentando-a à conveniência do capital financeiro das grandes corporações - um adulto em miniatura e ao mesmo tempo criança em suas espontaneidades e brincadeiras.

Nas mídias digitais, as crianças têm obtido visibilidade, principalmente no mercado publicitário, afirma Buckingham (2010, p.45) "[...] as crianças têm se tornado cada vez mais importantes não apenas como um mercado em si, mas também como um meio de se alcançar os mercados dos adultos [...]".
No cenário da sociedade em rede (Castells, 2015), da sociedade tecnomercadológica (Sodré, 2006, 2014), da sociedade do espetáculo (Debord, 2003), acredita-se por um lado na morte da infância (Postman, 2011) e, por outro, na sua reconfiguração através das mídias eletrônicas (Bukingham, 2010). Assim, as crianças são meros "fantoches" do sistema capitalista para potencializar o consumo (Moraes, 2006, 2016). Cabe questionar: as mídias digitais são vistas como possibilidades de crianças ocuparem um lugar de fala das redes sociais? As crianças são produtoras e/ou "iscas" de uma sociedade capitalista, do consumo, que tenta homogeneizálas?

No Brasil, uma pesquisa divulgada pelo IBOPE (2016), informa que crianças entre oito e doze anos de idade dedicam mais tempo com entretenimento eletrônico e digital do que com a escola e seus familiares, o que torna marcante a presença das mídias nas suas vidas e "[...] ditam opiniões, instituem costumes, ofertam modelos de pessoas, criam estilos de vida, colocam necessidades de consumo e modelos de felicidades" (Queiroz, 2013, p.57).

É importante ressaltar que a participação da criança no cenário midiático não é nova, e as mudanças ocorrem na forma como as crianças se relacionam com as mídias, atuando também na produção de conteúdos disseminados por meio das redes sociais a exemplo de Youtube, blogs, Instagram, Facebook, Twitter etc.

Em pesquisa divulgada em 2017, TIC Kids Online Brasil, pelo Centro Regional de Estudos para o Desenvolvimento da Sociedade da Informação (Cetic.br), cerca de oito em cada dez crianças e adolescentes (82\%), entre nove e dezessete anos de idade são internautas na rede mundial de computadores, o que corresponde a 24,3 milhões de crianças e adolescentes espalhados pelo país. 
No entanto, se formos pelos termos de legalidade de uso do Instagram, há restrições de sua utilização por crianças com idade inferior a treze anos. Assim, a condição necessária para criança participar da rede é assumida e tolerada publicamente por todos que participam do processo de interação via Instagram. Cabe, portanto, questionar: qual a participação e/ou capitalização das crianças e suas imagens para potencializar o consumo no mercado capitalista?

\section{METODOLOGÍA}

A investigação ora posta é de cunho qualitativa, com base na análise de conteúdo que, para Minayo (2003, p. 74), visa verificar hipóteses e ou descobrir o que está por trás de cada conteúdo manifesto. "[...] o que está escrito, falado, mapeado, figurativamente desenhado e/ ou simbolicamente explicitado sempre será o ponto de partida para a identificação do conteúdo manifesto (seja ele explícito e/ou latente)".

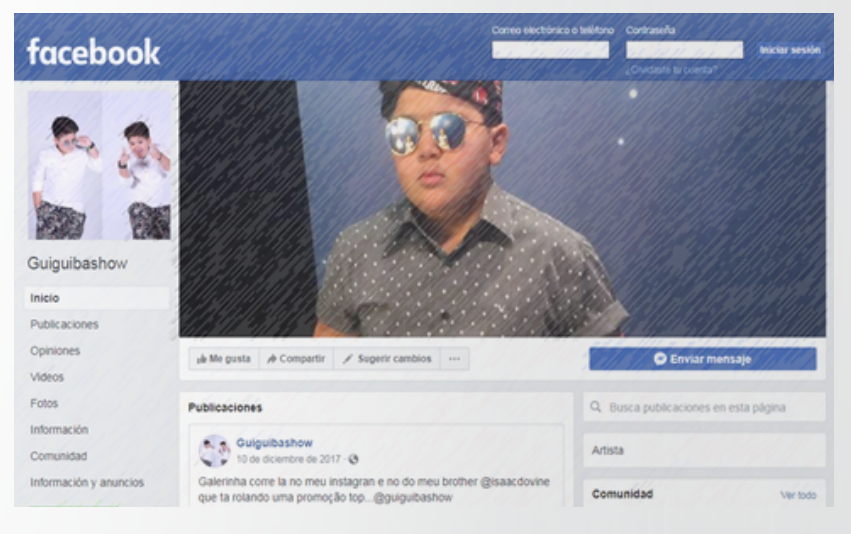

https://es-la.facebook.com/Guiguibashow-131762520696567/

Para o artigo, analisamos o perfil do instagramer Guilherme, que tem a marca de guiguiba.show. O perfil analisado é de uma criança de 7 anos de idade, residente em Teresina-Piauí, que teve notoriedade por meio da imitação do conhecido cantor de forró brasileiro Wesley Safadão. O perfil foi observado durante todo o dia 20 de dezembro de 2017, para identificar a movimentação do perfil: quantitativo de publicações, visualizações, seguidores e comentários como também identificar aspectos do consumo e de estilos de vida que o perfil dita para as crianças.

Os vídeos e fotografias postadas no perfil visibilizam as suas experiências cotidianas a exemplo de brincadeiras, estudos e viagens ao tempo em que divulga marcas e produtos "comprados" em lojas e/ou "recebidos de presente". O instagramer guiguibashow identificase como 'a criança mais famosa do Brasil', e registra quase meio milhão de seguidores até final 2017, com mais de mil e seiscentas imagens e vídeos publicados, a maioria com teor publicitário de marcas e produtos o que representa um poder simbólico para capitalização de sua imagem, pois quanto maior a quantidade de seguidores mais influência na rede social.

\section{GUIGUIBASHOW: A CRIANÇA (EN) CENA!}

A tecnologia permitiu ao indivíduo um palco onde ele pode apresentar e/ou representar sua performance virtual no mundo digital. Enquanto a aparência passa a fazer parte da gramática fundamental de reconhecimento, na medida em que nos tornamos perfeitamente estéticos, numa vida sem conflitos internos, a produtividade torna-se cada vez mais ligada ao produto em si. Influenciado pelo modo de operação do sistema capitalista, descobre-se que a imagem é um produto e, por esse produto, deve existir promessas que podem ser fetichizadas, numa proposta de imagem colocada à venda conforme seus objetivos de investimento. Esse "produto" deve ocupar os espaços e circuitos disponíveis induzindo ao seu consumo, o que Moraes (2016) chama de "lógica da coisificação", uma lógica que transforma objetos e pessoas em itens vendáveis e negociáveis. 


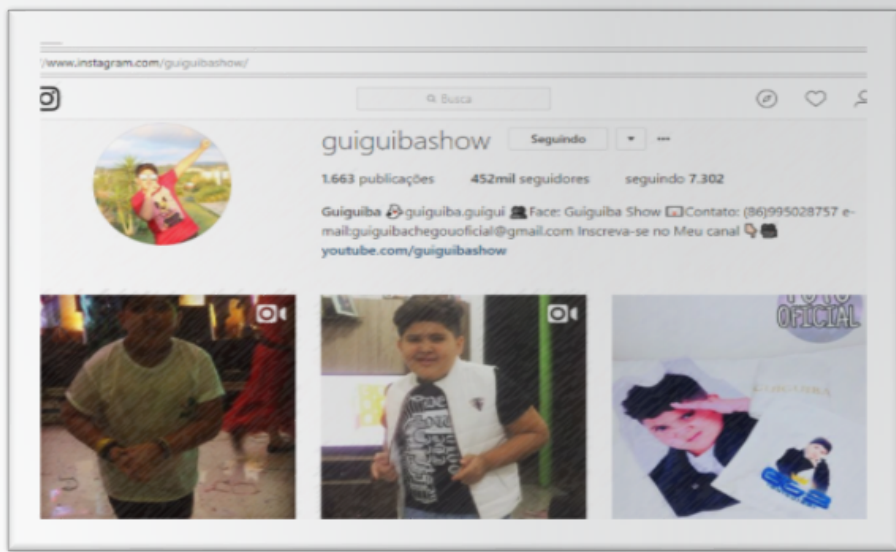

Perfil de Guiguibashow y su marca

Disponible en Instagram Guiguibashow, accedido el 20.12.2017.

Essa coisificação e "produtização" do indivíduo encontra um amplo espaço a ser explorado na internet, onde a cultura das mídias permite o acoplamento os dispositivos tecnológicos de informação e comunicação ao capital financeiro, tornando-se alvo cobiçado pelas corporações para ampliar suas fronteiras de expansão. De acordo com Moraes (2016), essas fronteiras se alargam através da publicidade, comércio eletrônico, exposição de marcas, audiovisual, patrocínio e monitoramento das redes sociais.

É, nesse cenário, que se apresenta a criança Guilherme por meio da marca Guiguibashow. Veja, a seguir, o perfil, print de vídeos e imagens do cotidiano virtual da referida criança.

\subsection{PERFIL DE GUIGUIBASHOW}

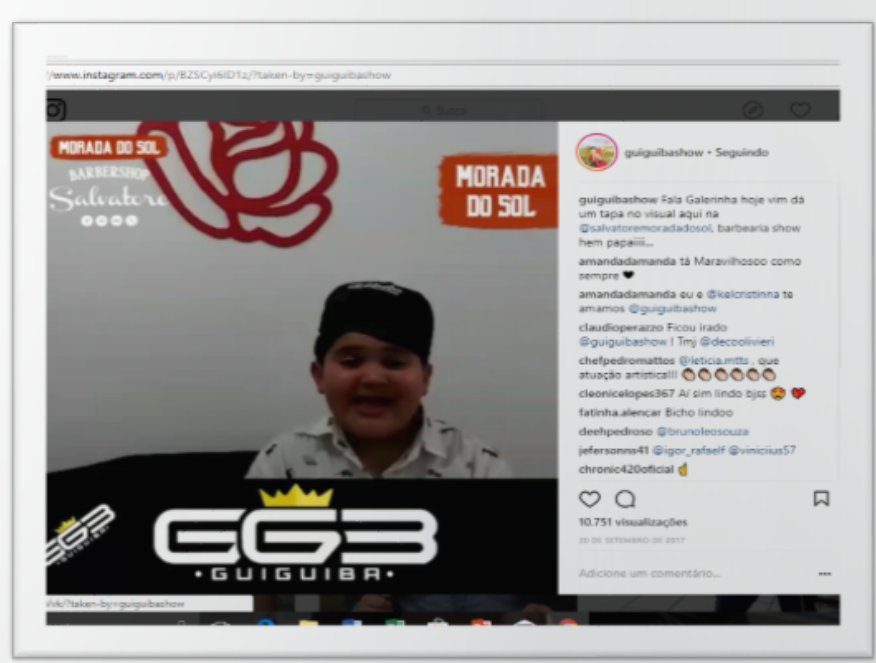

Perfil do Guiguibashow e sua marca.

Disponível em Instagram Guiguibashow, acessado em 20.12.2017
O perfil de Guiguibashow informa que, até esse período, realizou 1.663 publicações e tem 452 mil seguidores, e publiciza informações para contatos e contratações. Apresenta sua marca, definindo-o como "rei das crianças" (ao apresentar uma coroa) ao tempo que também faz publicidade de uma barbearia (vice-versa). Para Klein (2003, p.175-176), "[...] o que se quer não é tantos consumidores, mas uma tribo de fies que seguirão sua empresa, sua marca, como se seguisse a banda de rock predileta ou seu herói esportivo [...] por que a marca exige absorção constante de tudo o que tem significado e é novo em nossa cultura."

Na imagem postada abaixo, vê-se o encontro de Guiguiba com Wesley Safadão. A postagem no Instagram teve mais de 985 comentários, entre eles o de evapraeiro que diz O mininin q eu falei $q$ é daqui, e mais de 174.023 visualizações. É no espaço do Instagram, um dos alvos cobiçados pelo capital financeiro, que se fortalece a marca Guiguibashow, incentivando o consumo da marca Wesley Safadão.

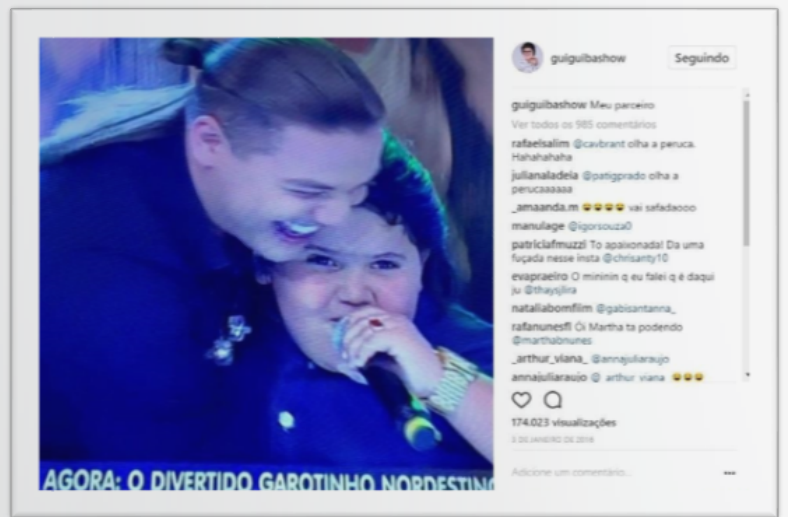

O encontro de Guiguibashow com Wesley Safadão. Disponível em Instagram Guiguibashow, acessado em 20.12.2017.

O investimento inicial na capitalização da imagem docantordeforró “WesleySafadão" porde Guiguiba foi fundamental para seu reconhecimento, nas janelas de visibilidades das mídias, definição do estilo de comportamento da marca Guiguibashow, à luz de novas técnicas de comercialização e publicidade, criação e veiculação, com 
participação de criança, assumindo, mas jamais declarado a mercantilização da infância e dos espaços virtuais. Tais investidas reforçam o consumismo, expandindo seus tentáculos em todo o ciberespaço, afirma Sodré (2016).

É importante considerar, conforme Buckingham (2010), a interação das crianças com as mídias eletrônicas é irreversível e suas experiências com essas mídias são repletas de narrativas influenciadas por discursos de grandes corporações. Assim, o debate centra-se não somente na utilização das mídias digitais pelas crianças, mas também nos conteúdos publicitários que estão participando, produzindo e veiculando nos espaços virtuais.

As crianças. Os direitos. A participação. A manipulação. A liberdade de expressão. Que protagonismos têm a criança na era das mídias digitais? Que protagonismos têm na sociedade capitalista? A convenção da ONU (1990), define crianças "todo ser humano com menos de 18 anos de idade, a não ser que, em conformidade com a lei aplicável à criança, a maioridade seja alcançada antes (Parte I, Art. 1). De acordo com a ONU (1990, Art. 13):

1 - A criança terá direito à liberdade de expressão. Esse direito incluirá a liberdade de procurar, receber e divulgar informações e ideias de todo tipo, independentemente de fronteiras, de forma oral, escrita ou impressa, por meio das artes ou de qualquer outro meio escolhido pela criança.

2 - O exercício de tal direito poderá estar sujeito a determinadas restrições, que serão unicamente as previstas pela lei e consideradas necessárias: a) para o respeito dos direitos ou da reputação dos demais; ou b) para a proteção da segurança nacional ou da ordem pública, ou para proteger a saúde e a moral públicas.

Nessa perspectiva, as crianças têm direito à liberdade de expressão, lazer e participação na vida cultural. Mas a vida cultural está atravessada pela atuação das mídias (sociedade em midiatização). É importante, então, questionar: a criança participa ou é "isca" das grandes corporações? Tal apropriação da indústria fazendo uso do uso direito de participação da criança é perceptível a partir da observação do perfil "Guiguibashow".

Ainda, no perfil Guiguibashow, temos a exposição de itens também fora do eixo geracional da infância e que são apresentados pela/para crianças como sendo possíveis de consumo. Embora o produto - um automóvel, por exemplo, não seja produzido para o consumo da criança, há estímulos ao seu consumo, a exemplo da imagem a seguir:

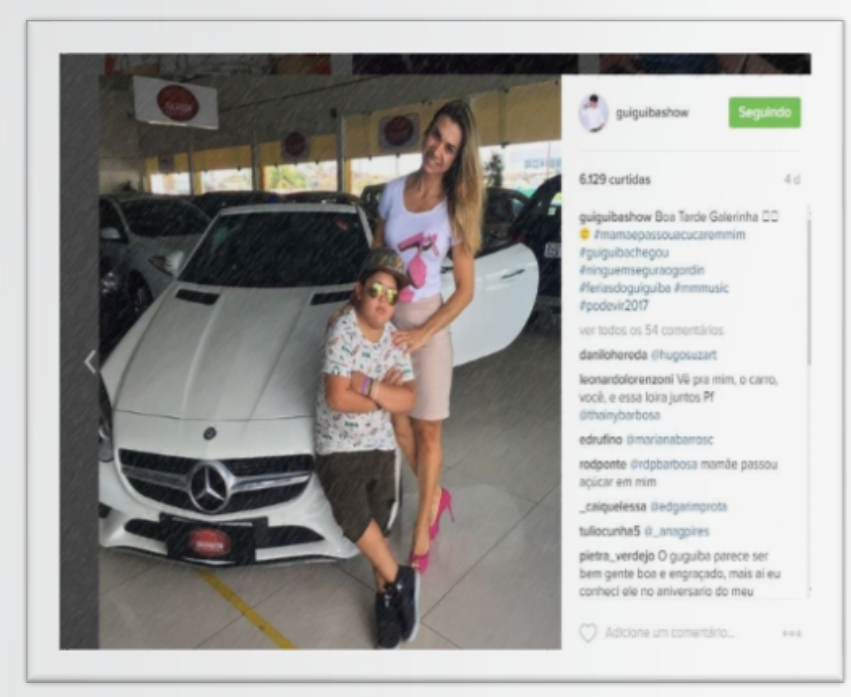

"Guiguibashow" na publicidade de uma marca de automóvel. Disponível em Instagram Guiguibashow, acessado em 20.12.2017.

$\mathrm{Na}$ imagem acima, a Guiguibashow está pousando com uma mulher ao lado de um automóvel de marca Mercedes-Benz, identificado pelo símbolo da marca. $\mathrm{Na}$ legenda contém informações narcisistas de autoelogio como \#mamãepassouaçúcaremmim, \#fériasdoguiguiba, \#Guiguibachegou, \#podevir2017, \#ninguémseguraogordinho que incentiva ao consumo do produto e ao estilo de vida de quem o consome, o que remete a um estilo de vida de um homem rico, bom vivant e galanteador.

A postagem reproduz modelos hegemônicos machistas e elitistas da sociedade capitalista. Hegemônico porque coadunam com a proposta de incentivar o consumo como uma forma de 
relacionamento e interações. Machista por induzir que um homem (mesmo criança) por meio de um bem material luxuoso atraia belas mulheres, além de objetificar a mulher. Elitista por exibir um automóvel, modelo luxuoso do mercado automobilístico, da marca Mercedes-Benz, de consumo de um restrito grupo de pessoas.

Elaine Carozzi (apud Moraes, 2016, p.182), diz que a marca do automóvel acima mira a sofisticação e:

Criar uma identidade de marca a ponto de transformála em luxo exige uma forte diferenciação construída por anos e anos de ações assertivas e consistentes, que busquem uma imagem maculada e ligada a valores como conquista, distinção social e poder.

Acredita-se que é possível estabelecer com os consumidores uma relação com marca mais humana do que uma entidade impessoal aberta. Ou seja, Guiguibashow é a "isca" para atingir identificação do público com a marca do automóvel. A estratégia em utilizar Guiguibashow para publicidade, ainda que não seja "moralmente aceito", consiste numa estratégia de mercado para atrair consumidores, em específico o público adulto.

Tem vida mais barata, mas não presta passou a ser um dos lemas de Guiguibashow, sendo recebida e reproduzida por sua audiência no Instagram. Ao postar imagens de um automóvel importado acompanhado de uma mulher, o valor agregado a imagem atribui um estilo de vida que "presta" ou é "digna". Tal comportamento poderia ser interpretado como negação da infância, uma vez que criança não tem habilidades para dirigir nem autorização legal para consumir um automóvel e/ ou manter relações com uma mulher.

É importante ressaltar que a simples prática de criar um perfil e postar fotos possui diferentes consoantes, capacidades e vontades de quem faz, de quem está na rede e de quem as consome. Essas consoantes diferem de acordo com temáticas e finalidade do blog. É possível que a maioria dos seguidores de Guiguibashow coadunem com o eu narcísico da criança-adulto show, no entanto, deve-se considerar que há espaço para a crítica e recepção negativa de conteúdo. Vejamos pela imagem a seguir, alguns comentários recebidos ainda na publicidade de Guiguibashow da marca de automóvel:

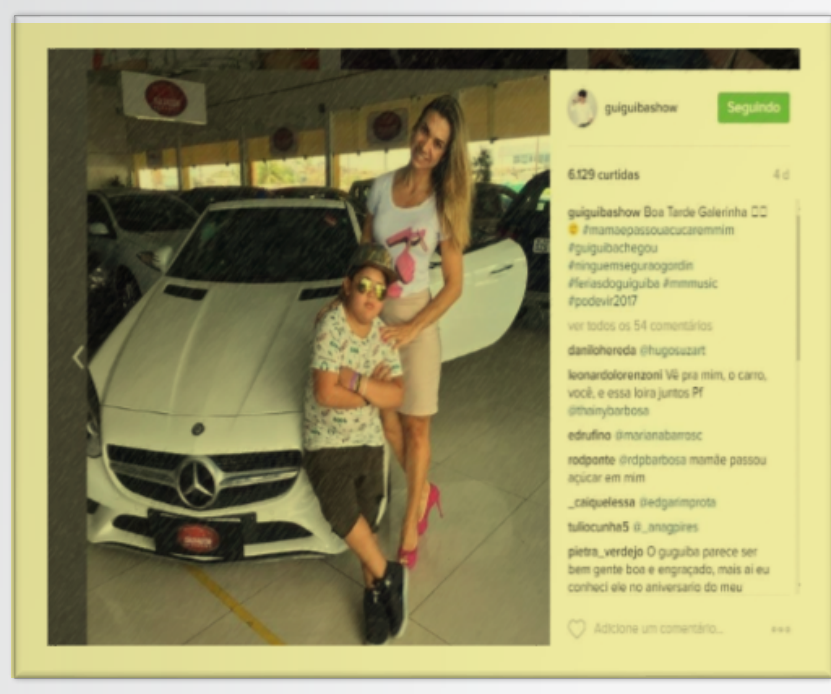

Comentários do pública acerca da postagem de "Guiguibashow"

na publicidade de uma marca de automóveis Disponível em Instagram Guiguibashow, acessado em 20.12.2017.

Pelos comentários inscritos na postagem podemos perceber que a vida de "Guiguiba", enquanto show/espetáculo (Guiguibashow), causou questionamentos sobre a sua posição fora da mídia, enquanto a criança Guilherme. Vejam:

Esse fdp é mt otário se for falar com ele, o cara se acha o fodão.

Ele é uma criança gente...Passada quem é essa mulher???

Ele é a desumildade em pessoa, qnd a pessoa vai falar ele, ele manda se foder. Não consigo entender como que essa criança faz sucesso.

O fato de ser criança e comportar-se como um adulto em miniatura é um dos elementos de crítica do público. Assim, confunde-se a performance como Guiguibashow e Guilherme. Observamos também o tipo de linguagem, palavras abreviadas, 
utilizada na mídia digital Instagram, a exemplo de "fdp", "mt", "qnd" (que significa "filho da puta", "muito" e "quando"), e a marcação de nomes de outros usuários, perceptíveis através do sinal de arroba (@) seguido do nome identificado no perfil a ser citado.

Os comentários flutuam em múltiplas direções e apontam para a relação da criança com as mídias sob formas de sentimentalismos. Ora condiz com o indicativo de proteção e preservação da infância, vista como vulnerável e, portanto, necessitada de supervisão dos adultos. Ora condiz com a sua atuação como Guiguibashow, uma criança ativa e protagonista no campo das mídias.

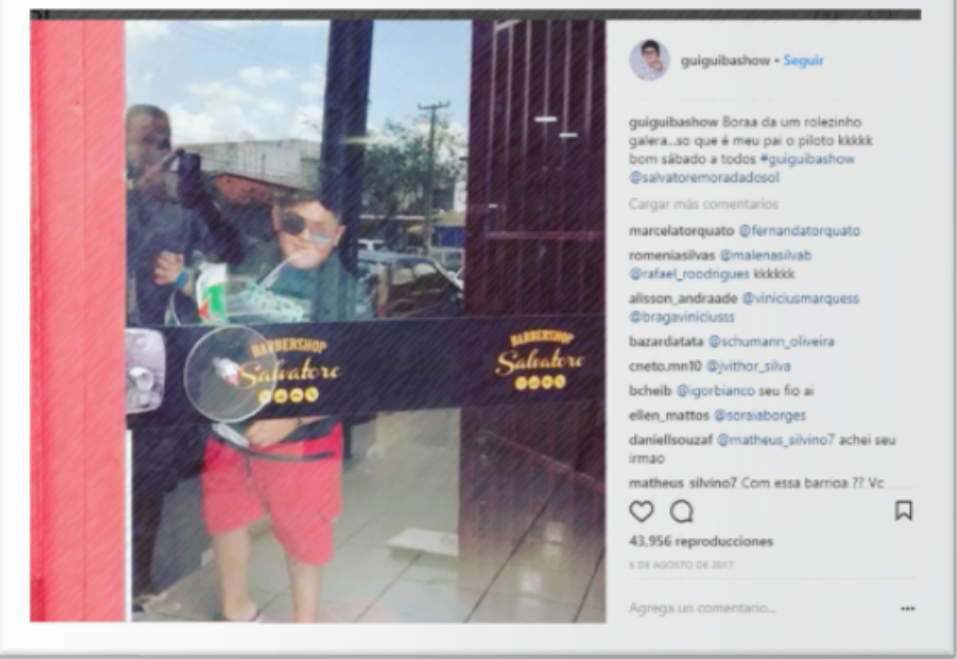

É, por meio do perfil no Instagram, que Guiguibashow divulga imagens de sua vida profissional, realizando atividades de sua rotina que se transforma comercial publicitário de marcas e produtos, conforme imagens a seguir:
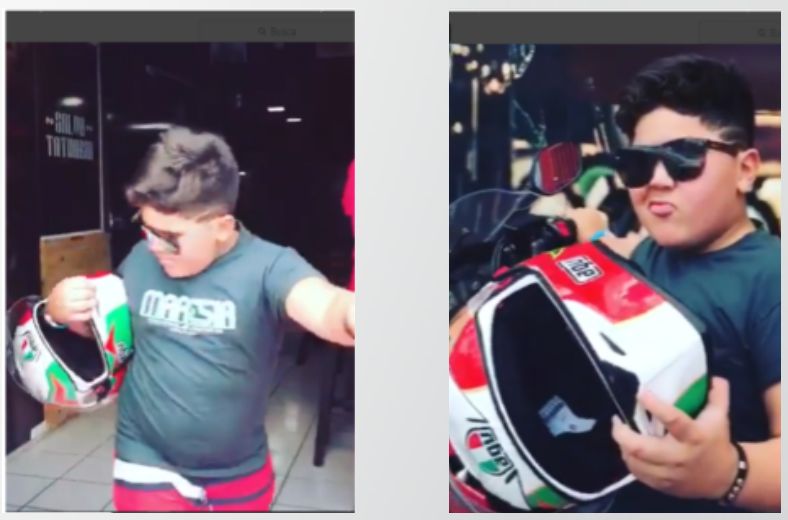

A publicidade rotineira de Guiguibashow no Instagram. Disponível em Instagram Guiguibashow, acessado em 20.12.2017.

O vídeo publicado no Instagram, com mais de 43 mil visualizações, Guilherme torna-se um suporte de venda das marcas e produtos, e modos de comportar-se na infância, como as estampadas na porta do estabelecimento, na camisa, no capacete, na motocicleta. No vídeo, Guiguibashow ao sair do estabelecimento comercial cujo nome aparece na porta diz: Quem é que vai querer uma carona com o papai? Em seguida, segue até a motocicleta, movimenta o comando de acelerar, olha para a câmera e diz: Existe vida mais barata, mas não presta não, frase reproduzida ativamente por ele.

No vídeo de 30 segundos, percebemos conforme Gaskell e Bauer (2002), as propostas de enquadramento, onde os sentidos e composições não são definidos apenas por elementos verbais. Guiguibashow fala apenas duas frases, mas a composição e cenário apresentam vários elementos e marcas que reforçam a mercantilização da infância: marca da roupa, do capacete, da motocicleta, dos óculos, da barbearia. Aliás, acerca da barbearia, caberia questionamento: o que uma criança faz em uma barbearia se, dentro da proporção biológica natural dominante, ela não tem barba? Tal comportamento poderia ser interpretado como negação da infância, uma vez que criança não tem legalmente condições de possuir carro, moto e, nem condições biológicas, de ter barba.

Diante do exposto até aqui, cabe ainda questionar: o investimento na imagem e no estilo de vida representa uma carreira dominada pelo valor de imagem e sua referência material, no caso, uma profissão. Guguibashow pode ser um personagem profissional de Guilherme? 


\section{CONSIDERAÇÕES}

Aplicativos como o Instagram constituem espaço para exposição da vida privada, em situações em que as imagens se associam às marcas e produtos, interpeladas por discursos mercadológicos que tendem a conduzir o universo infantil ao mundo dos objetos, marcas e suas relações simbólicas, e esmaecer as linhas fronteiriças entre a vida adulta e a vida infantil. Se é o contexto social que define o comportamento infantil e os modos como eles são apresentados, o contexto midiático em que elas estão inseridas é caracterizado por uma cultura que reduz as subjetividades de suas vivências ao universo do consumo, onde o brincar e o se comportar infantil incorpora tais referências.

Nessa perspectiva, a reflexão deve desenvolver-se também para a interação social familiar e os limites e consequências da exposição midiática, onde a reconfiguração dos espaços, fronteiras e limites de acessos e exposição a essas mídias deve ser debatida e analisada do ponto de vista social.

O que está em questão não é somente o direito de participação ativo da criança nas mídias, mas como participa e que escolhas têm nas ofertas e/ou no que Ihes é oferecido. Nesse direito de participação, cria-se a expectativa da criança ouvir e expressar a si mesma, sua cultura e sua linguagem e experiências de vida. Dessa forma, tanto o direito de participação quanto o direito à liberdade de expressão deve ser desenvolvido a partir das habilidades de educação e buscar ampliar a participação ativa e informada das crianças na cultura da mídia.

Porém, cabe refletir, a apropriação pelas grandes corporações do capital financeiro das crianças para fortalecer o consumo, utilizando-as como "iscas" incentivadoras do consumo como suporte de vendas de marcas, produtos e estilos de vida, mercantilizando assim a infância.

\section{REFERÊNCIAS}

- Buckingham, D. (2010). Crescer na era das mídias eletrônicas. São Paulo: Loyola.

- _ (2012). Repensando a criançaconsumidora: Novas Práticas, Novos Paradigmas. In: Comunicação, Midia e Consumo. São Paulo: ESPM, vol. 9.

- Castells, Manuel. (2015). O poder da Comunicação. Rio de Janeiro: Paz e Terra. (1999). A sociedade em rede: a era da informação, economia, sociedade e cultura. São Paulo: Paz e Terra.
- Cetic. (2017). Centro de estudos sobre as tecnologias da informação e da comunicação. Disponivel em: http://cetic.br, acessado em 19.12.

- Debord. G. (2003). Sociedade do espetáculo. eBooksBrasil, acessado em 15 de janeiro de 2018.

- Gaskell, George; BAUER, M. (2002). Pesquisa qualitativa contexto, imagem e som: um manual prático. Petropólis: Vozes.

- Giddens, A. (2002). Modernidade e Identidade. Rio de Janeiro: Zahar.

- Moraes, D. (2016). Crítica da mídia \& Hegemonia cultural. Rio de Janeiro: MAUAD x, Faperj.

- Klein, Naomi. (2003). Marcas globais e poder corporativo. In: Por uma outra comunicação. Rio de Janeiro: Record.

- Postman, N. (1999). O Desaparecimento da Infância. Rio de Janeiro, RJ: Graphia Editoral.

- Queiroz, M. (2013). Eu não quero ser a mulher saliente! Eu prefiro ser a Isabella Swan! Apropriações das identidades femininas por crianças na recepção midiática. Tese de Doutorado em Comunicação, Universidade do Vale do Rio dos Sinos (UNISINOS), Rio Grande do Sul, São Leopoldo, RS, Brasil.

- Sibilia, P. (2011). O show do eu: a intimidade como espetáculo. Rio de Janeiro: Nova Fronteira.

- Sodré, M. (2014). A ciência do comum - Notas para o método comunicacional. Petrópolis, RJ: Vozes.

- (2006). Antropológica do espelho: uma teoria da comunicação linear e em rede. Petrópolis, RJ: Vozes.

(2013). A mercantilização da internet e das redes sociais. Acessado em https:// blogdaboitempo.com.br

\section{NOTAS}

[1] Se formos pelos termos de legalidade de uso do Instagram há restrições de sua utilização por crianças com idade inferior a 13 anos. Assim, a condição necessária para criança participar da rede é assumida e tolerada publicamente por todos que participam do processo de interação via Instagram.

\section{Para citar este artigo:}

Azevedo - Queiroz, M. y Alves dos Santos - Moura Fé, F. (2018). GUISABASHOW. CRIANÇA-ADULTO SHOW. Mercantilização de crianças no Instagram. Revista Luciérnaga / Comunicación. Año 10, N19. Págs.53-61.

DOI. 10.33571/revistaluciernaga.v10n19a4

OJS. http://revistas.elpoli.edu.co/index.php/luc/issue/archive Link. http://www.politecnicojic.edu.co/index.php/revista-luciernaga 